DOI : 10.33451/florafauna.v26i1pp65-68

FLORA AND FAUNA

ISSN 2456 - 9364 (Online)

2020 Vol. 26 No. 1 PP 65-68

ISSN 0971 - 6920 (Print)

\title{
Carbamate, Organophosphate and Organochlorine Pesticidal Effect on the Qualitative Occurrence and Survivability of Blue-green Algae
}

\section{Ganesh S. Shinde}

\author{
Department of Botany, \\ K.J. Somaiya College of Arts, Commerce and Science, \\ KOPARGAON, Dist. AHMEDNAGAR-423 601 (M.S.), INDIA \\ Email-gsshindebhumi@gmail.com
}

\section{Received : 28.02.2020; Accepted : 22.04.2020}

\begin{abstract}
Blue-green algae make a valuable contribution to the nitrogenous soil fertility by fixing atmospheric nitrogen and are of great agricultural importance as biofertilizer. Four commercial grade pesticides, Carbamate, Furadan and Sevin and Organophosphate, Rogor and Organochlorine, Endotaf were used to study their effect on the survivability and qualitative occurrence of blue-green algae by taking survival on the control plate as $100 \%$. Stock solutions of these pesticides were prepared freshly for experiments in the sterilized BG-11 media and added to the culture media to obtain the desired concentrations of 100, 250, 500 and 1000 ppm. After 30 days of incubation, the blue-green algal forms appeared in the culture flask were identified using standard monographs. The pragmatic results indicated that, soil blue-green algae show variable resistance to pesticide treatments. The survival percentage of the tested blue-green algae was reduced upto 50 percent at 500 ppm of carbamate pesticides, Furadan and Sevin. While with Rogor only $10.52 \%$ and Endotaf $5.26 \%$ survivability was noticed at $500 \mathrm{ppm}$ dose level. Furthermore, the organochlorine pesticide Endotaf was more toxic than the organophosphate, Rogor and the carbamates, Sevin and Furadan in sequence to the blue-green algae. It was cocluded that higher doses of pesticide application in the crop fields i.e. more than 100 ppm of Furadan, Sevin and Rogor and even at 100 ppm of Endotaf, qualitative and quantitative occurrence of heterocystous and non- heterocystous blue-green algae was decreased considerably. This suggests that, indiscriminate use of these pesticides may cause adverse effects on the nitrogen fixing blue-green algae of various crop fields, which has a direct influence on total productivity. In general, the sensitiveness of different blue-green algae to pesticide application was found to be more in sheathless heterocystous and unicellular forms than the heterocystous ensheathed and non- heterocystous ensheathed forms.
\end{abstract}

Figure : 00

References : 09

Table : 01

KEY WORDS : Blue-green algae, Endotaf Pesticides, Furadan, Qualitative Occurrence, Rogor, Sevin.

\section{Introduction}

In recent years, the practice of utilizing blue-green algae as an efficient source of biofertilizer for various crops has been advocated and adopted in India. They have tremendous potential in environmental management as soil conditioner, biomonitors of soil fertility, water quality, feed for animals and protein supplements. Reduction of chemical fertilizers input upto $30 \%$ by supplementing with blue-green algae as a significant finding when conservation of energy is contemplated.

One of the problem that has been noticed under field conditions is the destruction of blue-green algal populations by pesticide application intended to control the insects and pests of the various agricultural crops. These agrochemicals also damage wide variety of beneficial microorganisms because of their long persistence in the environment ${ }^{1}$. Therefore, pesticides used in routine applications in crop fields have important ecological effects in addition to those usually intended.

In agriculture, introduction of fertilizer responsive crop varieties has necessitated the use of enormous amounts of pesticides during production and storage. Many chlorinated and organophosphorus pesticides, which are not readily soluble in water, are emulsified. These are dispersed in water as fine particles that are attracted to surfaces. This affinity results in their accumulation through adsorption on to the surface of living organisms $^{2}$. The present data suggest that cyanobacterial forms used in biofertilizers are capable of tolerating pesticide levels recommended for field applications. 
By considering all these issues along with societal responsibilities as well as to fulfill the lacunae, the present investigation was carried out to assess the effect of pesticides on the survivability of nitrogen fixing blue-green algae isolated from soil covering various agro-practices areas of Kopargaon tahsil, Ahmednagar district.

\section{Materials and Methods}

During the present investigation, four commercial grade pesticides, carbamate, Furadan and Sevin (Union Carbide Ltd.) and organophosphate, Rogor and organochlorine, Endotaf (Rallis India Ltd.) were used. Stock solutions of these pesticides were prepared freshly for experiments in the sterilized media and added to the culture media to obtain the desired concentrations of 100 , 250, 500 and $1000 \mathrm{ppm}$. The $\mathrm{pH}$ of all the media was adjusted to 7.5. Ten g proportions of air dried soil was taken in cotton stoppered, sterilized conical flasks and then $50 \mathrm{ml}$ of the BG- 11 medium (with different concentrations of various pesticides) was added into each flask. After addition of nutrient medium to the culture, samples were agitated to ensure an uniform distribution of the pesticides. For each treatment, triplicates were set up and incubated at $28 \pm 2^{\circ} \mathrm{C}$ under $16 / 8$ hours light/ dark cycles with 2- $5 \mathrm{~K}$ Lux light intensity from white fluorescent tubes.

The blue-green algal forms appeared in the culture flask after 30 days of incubation were identified using standard monographs ${ }^{3-5}$. The survival percentage of the blue-green algae was calculated in the laboratory cultures on the basis of the number of species present in the respective treatments by taking survival in the control flask as $100 \%$.

\section{Results}

Altogether nineteen blue-green algal taxa appeared in the composite soils of the control flasks belonging to 14 genera and six families. These species belonged to three orders viz. Chroococcales, Nostocales and Stigonematales. The order Chroococcales represented by 3 genera and 3 species, which embraced Chroococcus minutus, Gloeocapsa kuetzingiana and Aphanothece pallida. The order Nostocales represented by 9 genera, among which family Oscillatoriaceae comprises 3 genera and 4 species viz. Oscillatoria okeni, O. animalis, Phormidium fragile and Lyngbya polysiphoniae. The family Nostocaceae represented by 4 genera and 8 species, which are Cylindrospermum musicola, Nostoc punctiforme, N. paludosum, N. Linckia, N. calcicola, Anabaena oryzae, A. fertilissima and Aulosira aenigmatica. The family Scytonemataceae and Rivulariaceae comprises single genus each with its species viz. Scytonema subtile and Calothrix javanica. While the order Stigonematales represented by 2 genera with its species, Hapalosiphon welwitschii and Westiellopsis prolifica belong to single family Stigonemataceae.

Amongst the nineteen blue-green algal species appeared in the control flask 7 species were nonheterocystous and 12 were heterocystous. Nostoc punctiforme, Anabaena fertilissima, Hapalosiphon welwitschii and Westiellopsis prolifica were present abundantly in the test soils, have been reported to fix atmospheric nitrogen in pure culture ${ }^{6}$ and thus suggesting the richness of beneficial blue-green algal species in the soils of the study areas.

The results depicted in the Table- 1 revealed that, the occurrence of blue-green algae remained almost unaffected even in the presence of Furadan, Sevin and Rogor pesticides at $100 \mathrm{ppm}$ dose in the test soil. However, their quantitative occurrence was decreased to a considerable extent.

Further increase in the pesticide dose level, proportionatly decreases their occurrence was noted. At $500 \mathrm{ppm}$ dose level of the carbamate pesticides Furadan and Sevin, most of the unicellular and filamentous forms of the blue-green algae could not grow in the test soils. Exception to this is the blue-green algal species, Gloeocapsa kuetzingiana, Lyngbya polysiphoniae, Scytonema subtile and Calothrix javanica, which possess well-defined sheath around their cells or trichomes. While, none of the other blue-green algal taxa tested could tolerate 1000 ppm concentration of the carbamate pesticides, Furadan and Sevin.

The effect of the organophosphate pesticide, Rogor and organochlorine, Endotaf was quite specific on the occurrence of blue-green algal forms. Even at $100 \mathrm{ppm}$ of Rogor and Endotaf, qualitative and quantitative occurrence of heterocystous and non- heterocystous blue-green algae was decreased considerably. These algal species were almost completely eliminated from the soils in presence of 500 ppm concentration of Rogor and Endotaf pesticides. With further increase in the pesticides concentration, almost all the blue-green algal forms did not grow in the culture. Only Lyngbya polysiphoniae and Calothrix javanica tolerated upto 500 ppm of Rogor. However, few filaments of Lyngbya polysiphoniae appeared in the soils supplemented with 500 ppm of Endotaf. Further increase in pesticides concentration at 1000 ppm of Rogor and Endotaf, none of the blue-green algal species could grow.

The pragmatic results indicated that, soil bluegreen algae show variable resistance to pesticide treatments. The survival percentage of the blue-green algae was reduced upto 50 percent at $500 \mathrm{ppm}$ of carbamate pesticides, Furadan and Sevin. While with Rogor only 
Carbamate, Organophosphate and Organochlorine Pesticidal Effect on the Qualitative Occurrence and Survivability of Blue-green Algae 67

TABLE-1: Quantitative occurrence of blue-green algal species and their survival percentage in presence of various concentrations of pesticides in cultures.

\begin{tabular}{|c|c|c|c|c|c|}
\hline \multirow[t]{3}{*}{ Pesticide } & \multirow{3}{*}{$\begin{array}{l}\text { Concentration } \\
(p p m)\end{array}$} & \multicolumn{4}{|c|}{ Blue-green Algae } \\
\hline & & \multicolumn{2}{|c|}{ Heterocystous } & \multicolumn{2}{|c|}{ Non- heterocystous } \\
\hline & & $\begin{array}{c}\text { Total } \\
\text { no. of } \\
\text { species }\end{array}$ & $\begin{array}{c}\text { Percentage } \\
\text { survival }\end{array}$ & $\begin{array}{c}\text { Total } \\
\text { no. of } \\
\text { species }\end{array}$ & $\begin{array}{c}\text { Percentage } \\
\text { survival }\end{array}$ \\
\hline Control & Without Pesticide & 16 & 100 & 03 & 100 \\
\hline \multirow[t]{4}{*}{ Furadan } & 100 & 16 & 100 & 03 & 100 \\
\hline & 250 & 15 & 93.7 & 03 & 100 \\
\hline & 500 & 08 & 50 & 02 & 66.6 \\
\hline & 1000 & 03 & 18.7 & 01 & 33.3 \\
\hline \multirow[t]{4}{*}{ Sevin } & 100 & 14 & 87.5 & 03 & 100 \\
\hline & 250 & 13 & 81.2 & 03 & 100 \\
\hline & 500 & 07 & 43.7 & 02 & 66.6 \\
\hline & 1000 & 01 & 6.2 & 01 & 33.3 \\
\hline \multirow[t]{4}{*}{ Rogor } & 100 & 16 & 100 & 03 & 100 \\
\hline & 250 & 11 & 68.7 & 02 & 66.6 \\
\hline & 500 & 02 & 12.5 & 00 & 00 \\
\hline & 1000 & 00 & 00 & 00 & 00 \\
\hline \multirow[t]{4}{*}{ Endotaf } & 100 & 11 & 68.7 & 02 & 66.6 \\
\hline & 250 & 01 & 6.2 & 01 & 33.3 \\
\hline & 500 & 01 & 6.2 & 00 & 00 \\
\hline & 1000 & 00 & 00 & 00 & 00 \\
\hline
\end{tabular}

$10.52 \%$ and Endotaf $5.26 \%$ survivability was noticed at 500 ppm dose level.

\section{Discussion}

The results obtained regarding the survivability of blue-green algae showed that, the organochlorine pesticide Endotaf was more toxic than the organophosphate, Rogor and the carbamates, Sevin and Furadan in sequence to the tested blue-green algae. Accordingly ${ }^{7}$, exposure to organochlorine compounds can inhibit enzyme activity and photosynthesis, alter cell membrane permeability and integrity and interfere with synthesis of DNA, RNA and proteins. In this view organochlorine pesticides have been considered to be hazardous due to their toxicity and longer 
persistence in the environment. Likewise ${ }^{8}$, studied comparative tolerance of Isoproturon, Saturn and BHC on a heterocystous cyanobacterium Cylindrospermum majus and concluded that the level of tolerance was upto $300 \mu \mathrm{g} / \mathrm{ml}$ for Isoproturon and Saturn, while it was $0.5 \mu \mathrm{g} /$ $\mathrm{ml}$ for $\mathrm{BHC}^{9}$ revealed the average acute toxicity of the carbamate insecticides to the cyanobacteria and the green algae in the descending order of carbaryl > carbofuran, Propoxur, Metolcarb $>$ carbosulfan.

\section{Conclusions}

It was clearly seen that higher doses of pesticide application in the crop fields i.e. more than $100 \mathrm{ppm}$ of Furadan, Sevin and Rogor and even at 100 ppm of Endotaf, qualitative and quantitative occurrence of heterocystous and non- heterocystous blue-green algae was decreased considerably. In general, the sensitiveness of different bluegreen algae to pesticide application was found to be more in sheathless heterocystous and unicellular forms than the heterocystous ensheathed and non- heterocystous ensheathed forms. The mechanism of resistance of the ensheathed blue-green algae to the pesticides is possibly due to the presence of sheath outside the cell wall of these algae, which might be protecting them from the adverse effect of the toxic chemicals.

This suggests that indiscriminate use of these pesticides may cause adverse effects on the nitrogen fixing blue-green algae of various crop fields, which has a direct influence on total productivity. Such investigations are useful in awakening the farmers to adopt better farm management practices that in turn will reduce the chemical pesticides input and problem of environmental degradation.

\section{References}

1. Anand N. Handbook of blue-green algae, Publ. Bishen Singh Mahendra Pal Singh, Dehradun, India. 1990; 1-79.

2. Desikachary TV. Cyanophyta. I.C.A.R. Publication, New Delhi. 1959 ; 1-686.

3. Kapoor K, Arora L. Comparative studies on the effect of pesticides on nitrogen-fixing Cylindrospermum majus Kutz. ex Born. et Flah. Indian J. Environ Sci. 2000; 4 (1): 89-96.

4. Lal R, Saxena DM. Cytological biochemical effects of pesticides on microorganisms. Residue Reviews. 1980; 73: $49-86$.

5. Ma J, Lu N, Oin W, Xu R, Wang Y, Chen X. Differential responses of eight cyanobacterial and green algal species to carbamate insecticides. Ecotoxicol. Environ. Saf. 2006; 63 (2): 268-274.

6. Nayak H, Sahu JK, Adhikary SP. Blue green algae of rice fields of Orissa state II. Growth and nitrogen fixing potential. Phykos. 1997; 35: 111-118.

7. Padhy RN. Cyanobacteria and pesticides. Residue reviews. 1985; 95: 1-44.

8. Prescott GW. Algae of the Western Great Lakes Area. Publ. Otto Koeltz Science Publishers, Koeningstein. 1951; 1-935.

9. Venkataraman LV, Krishnakumari MK, Suvarnalatha G. Algae as a tool for biomonitoring and abatement of pesticide pollution in aquatic system. Phykos. 1994; 33 (1 and 2): 171-193. 